\title{
REFLETINDO SOBRE PROJETOS ESPORTIVOS SOCIAIS E A CAPOEIRA
}

Recebido em: 03/02/2014

Aceito em: 12/11/2014

Carlos Sérgio Rabelo da Conceição ${ }^{1}$ Leandro Ribeiro Palhares ${ }^{2}$

Universidade Federal dos Vales do Jequitinhonha e Mucuri, Diamantina - MG - Brasil

RESUMO: Este texto tem por objetivo apresentar e discutir os projetos esportivos sociais e a sua influência na vida de crianças e jovens. $O$ estudo se deu através de revisão bibliográfica em que se destacasse a relação dos projetos esportivos sociais e a vida de participantes desses projetos, tendo como referencial teórico a abordagem histórico-cultural de Vigotski. Como forma de exemplificação, foi usada a capoeira, identificando elementos como conceito histórico, implantação em projetos sociais e seus efeitos. Os projetos esportivos sociais vem ganhando destaque nos últimos anos e constitui uma nova forma de educação legítima no Brasil.

PALAVRAS CHAVE: Projetos. Atividades de Lazer. Esportes.

\section{REFLECTING ON SOCIAL SPORTS PROJECTS AND CAPOEIRA}

ABSTRACT: This paper aims to present and discuss the social sports projects and their influence on childhood and youth. The study was made through literature review that highlighted the relationship of social sports projects and the lives of participants in these projects, theoretically based in the cultural-historical approach of Vygotsky. As an example, capoeira was used to identify components as historical concept, deployment in social projects and their effects. The social sports projects have been highlighted lately and represent a new way of legitimate education in Brazil.

KEYWORDS: Projects. Leisure Activities. Sports.

\section{INTRODUÇÃO}

No Brasil, os jovens com idades entre 15 e 24 anos representam aproximadamente 34.081.330 de pessoas (IBGE, 2000) e são esses jovens o principal

\footnotetext{
${ }^{1}$ Discente do Curso de Educação Física da UFVJM.

${ }^{2}$ Doutorando em Estudos do Lazer - EEFFTO / UFMG. Docente do Departamento de Educação Física da UFVJM. Membro do Grupo Capoeira Gerais - Mestre Mão Branca.
} 
alvo de programas sociais. As lacunas do ensino regular e profissional associadas a outras mazelas no plano dos direitos sociais e políticos, além da ineficácia do Estado, ampliam as desigualdades sociais fragilizando ainda mais as populações menos favorecidas (CASTEL, 1999), empurrando muitos desses jovens para um mundo de extremas dificuldades. Para evitar tal situação se faz necessária a intervenção educacional em diferentes espaços e perspectivas paralelos à escola e seu arcabouço legal (CASTRO; ABRAMOVAY, 1998; GOHN, 2004; 2006), cuja finalidade principal é a transformação da sociedade a fim de torná-la mais justa e igualitária (FREIRE, 1980; NARANG, 1992).

Segundo Gohn (2004; 2006), as intervenções apontadas acima geralmente se sustentam em projetos sociais cujas atividades são baseadas em saberes e fazeres diferenciados através de jogos, musicalidade e esportes/atividades físicas, que podem variar das mais diversas formas e motivações dependendo de vários fatores, como região, cultura local e motivações pessoais (VIANNA; LOVISOLO, 2009).

Para Silveira (2013, p.7), os efeitos combinados da crise econômica e do fracasso da política educacional, associados à crescente participação dos jovens na criminalidade urbana violenta, fazem com que o esporte seja utilizado em ações, projetos e programas públicos ou privados, como estratégia capaz de conter ou disfarçar as mazelas sociais.

Contudo há duas visões em conflito nesse contexto: uma apologista, que diz respeito ao grande desenvolvimento em campos amplos na vida dos jovens atendidos por projetos sociais e outra crítica, com vistas contrárias aos projetos, a qual diz ser de responsabilidade dos governos a implementação de esportes, cultura, lazer e afins às crianças e adolescentes e não de empresas, ONGs e outros órgãos, pois os programas muitas vezes não tem continuidade e nem o compromisso de preparar a comunidade para a transformação de sua realidade e ainda salienta que tais responsabilidades são 
governamentais e não devem ser transferidas para a sociedade civil (THOMASSIM, 2006; SOUZA et al, 2010; SILVEIRA, 2013). Não é objeto deste artigo levar a diante a discussão das causas e consequências desse conflito; para maiores aprofundamentos consultar Vianna e Lovisolo (2009).

O esporte pode contribuir para as demandas sociais, não no sentido de as práticas esportivas/atividades físicas serem a solução para problemas sociais - uma visão apologista, funcionalista e "salvadora" das práticas corporais, mas uma possibilidade real e restrita à suas limitações e benefícios - motores, físicos, culturais e sociais (SOUZA; CASTRO; VIALICH, 2012; SILVEIRA, 2013). Os projetos sociais, especialmente os de caráter esportivo, têm como missão permitir que crianças e jovens possam construir coletivamente a sua história com o auxílio dos conteúdos da cultura corporal de movimento (STOROLI, 2007; PALHARES, 2012).

Cabe aqui pontuar sobre a nossa concepção de esporte. De modo geral entendese por esporte aquelas manifestações envoltas por regras, com um corpo específico de conhecimentos técnicos e táticos, gerenciadas por federações, com competições em diversos níveis e categorias e seus praticantes são atletas que visam o alto rendimento. Se solicitarmos às crianças e jovens atendidos pelos mais diversos projetos sociais esportivos exemplos de esportes certamente ouviremos: futebol, voleibol, basquetebol e futsal, em virtude da educação física escolar e por influência da mídia. Ocasionalmente (em época de Olimpíadas, por exemplo) poderemos ouvir natação, atletismo e judô. De acordo com Palhares (2012), estas práticas devem fazer parte de projetos sociais não porque são esportes, mas porque pertencem à cultura corporal de movimento.

No entanto, existem outras práticas corporais que também compõem a cultura corporal de movimento: a capoeira, as danças (clássicas, contemporâneas e folclóricas), 
as lutas, os jogos e as brincadeiras, as ginásticas (artística, rítmica, de academia) e os esportes pouco incentivados e/ou desconhecidos das comunidades atendidas pelos projetos sociais (como exemplos: tênis, futebol americano e peteca). Portanto, ao se falar de projetos sociais esportivos, o esporte tem de ser compreendido de maneira ampla, com uma visão crítica que deve ir além dos modismos e influências midiáticas, ou seja, como toda e qualquer manifestação da cultura corporal de movimento (PALHARES, 2012).

Apesar de entendermos que os projetos sociais devem contemplar não apenas os esportes, mas as mais diversas práticas corporais presentes na cultura corporal de movimentos, no presente artigo iremos nos referir à capoeira como parte integrante de projetos esportivos sociais (e não de projetos culturais ou artísticos), pois a mesma é assim contemplada nos editais de programas e projetos sociais e educativos tanto de empresas privadas quanto nas três esferas do setor público, além de ser assim compreendida e relativamente aceita no âmbito da Educação Física de modo geral.

Além disto, entendemos também que os esportes (aqui entendidos como cultura corporal de movimentos - as práticas corporais) vinculados a estes projetos sociais devem ser mediadores (atividades meio) de outros propósitos e não a atividade fim. Neste sentido, é possível vislumbrar nos projetos esportivos sociais a relação entre a capoeira, a cultura e o lazer. Segundo Marcelino (2004), lazer é a articulação entre tempo, espaço e conjunto de atividades/ações desenvolvidas no tempo livre e, portanto, cada projeto social deveria ser um espaço/tempo para que gestores, educadores e beneficiários, construam sua concepção de lazer, baseado na realidade individual e social (COUTO; COUTO, 2011). Assim, prática das mais diversas atividades, inclusive 
a capoeira, possibilita a experimentação, as tensões e as ressignificações de sentidos de crianças e jovens nos espaços e tempos dos projetos sociais (FARIA et al, 2011).

As reflexões descritas acima nos conduzem a um importante questionamento acerca dos projetos esportivos sociais: quais são as possíveis contribuições na vida de crianças e jovens? Portanto, o objetivo deste trabalho é refletir a importância dos projetos esportivos sociais, especialmente aqueles com ênfase na capoeira. Para tanto, a análise de tais contribuições na vida de jovens brasileiros será baseada na abordagem histórico-cultural, de Vigotski, que pressupõe a aprendizagem e o desenvolvimento a partir das relações sociais e experiências, mediadas e significadas por um grupo social (“o outro") e convertidas (“internalizadas") pelos praticantes, beneficiários dos projetos.

\section{ABORDAGEM HISTÓRICO-CULTURAL}

No presente artigo o referencial teórico adotado para compreender o ser humano e seus processos, sociais e individuais, de formação, cultural e identitária será a abordagem histórico-cultural. Para Vigotski a relação sujeito e objeto é mediada por signos, por exemplo, quando se aprende um gestual se aprende seus significados (sociais) e sentidos (pessoais). Aliás, só se aprende, internaliza, após aprender seus significados e estes passam a fazer sentido para nós. A aprendizagem em uma perspectiva histórico-cultural é aprender a construir sentidos e significados.

O crucial para todo o processo de desenvolvimento é o fato de que seu aperfeiçoamento vem de fora e é determinado pela vida social do grupo o qual o indivíduo pertence (STOROLI, 2007). A expressão "vem de fora" se remete a uma dicotomia ser humano-ambiente social como se nós não fizéssemos parte, integral e ativa, do meio em que vivemos (SMOLKA, 2000). E isso não caracteriza a proposta de 
Vigotski, pelo contrário, somos tão parte do meio que este apresenta algumas regras, noções e construtos, criados e significados por nós mesmos, que quando uma pessoa inicia em um novo ambiente ela tem de apreender tais significados (para os demais) e depois se apropriar dos mesmos (aqueles que fazem sentido para ela). Assim, pessoa e meio formam uma unidade, dinâmica e em permanente mudança.

Para Vigotski e Luria (1996), o ser humano se constitui na relação com o trabalho (suas produções), ou seja, na práxis; é nas relações sociais, na integração entre pessoas, que o aprendizado acontece, emergindo zonas de desenvolvimento iminente (ZDI): situações (oportunidades) desconhecidas que permitem variabilidade e novidade que consequente motivação e progressão. Para Vigotski a principal pergunta não é como alguém aprende, mas o que leva (motiva) alguém aprender. E é nesta subjetividade que o sujeito se singulariza nas relações sociais, dialéticas e conflitivas: do nível interpessoal para o nível intrapessoal (o "eu” se constitui na relação com o "nós”).

Para a teoria de Vigotski, cultura se apresenta como um fenômeno histórico e com forte relação com a mente humana: uso de instrumentos e signos com as formas específicas de vida social que esses instrumentos e signos medeiam. O desenvolvimento cultural é o mais elevado status do homem. O crucial para todo o processo de desenvolvimento é o fato de que seu aperfeiçoamento é determinado pela vida social do grupo o qual o indivíduo pertence. De acordo com Sirgado (2000a), Vigotski aponta três momentos do desenvolvimento cultural (em si; para os outros; para si) que, de modo geral, explica que os sujeitos tornam-se membros de um grupo social específico, se constituindo sujeitos individuais e únicos, porém formados, constituídos pela ação de um coletivo. 
O primeiro momento, "em si", é quando o sujeito ao se inserir em um determinado grupo social passa a observar os componentes daquele grupo, em relação ao seu gestual, linguagem, rituais, códigos, enfim, signos. Assim, um capoeirista iniciante observa e percebe os capoeiras mais experientes em relação a sua postura corporal, linguagens verbal e não verbal, os códigos de hierarquia e de comportamento que permeiam o cotidiano de um grupo de capoeira. A partir daí o capoeirista iniciante passa a se apropriar destes signos, tomando-os como seu para, em um primeiro momento, adquirir a aceitação dos demais membros que compõem o grupo, em especial os mais antigos e o Mestre. Este é o segundo momento do desenvolvimento cultural: "para os outros". Por fim, o terceiro momento, "para si", é o momento em que o capoeirista iniciante passa a resignificar aqueles signos que foram adquiridos, dando sentido pessoal a eles, quer dizer, resignificando-os. A partir de então o praticante tornase efetivamente um membro do grupo de capoeira, se constituindo um sujeito singular, porém constituído pela ação de um coletivo.

Em outras palavras, é como um indivíduo adquire, desenvolve e participa das experiências culturais. No exemplo do iniciante na capoeira, ele internaliza suas experiências culturais, quer dizer, aquilo que ele pratica, escuta, vê e observa dentro do grupo (“de fora para dentro”) para posteriormente significar para si aqueles valores (“de dentro para fora"), se apropriando daqueles saberes do grupo e agindo como um membro que se tornou.

Assim, um indivíduo se torna único por meio dos sentidos e significados atribuídos às experiências de aprendizagens vividas e compartilhadas. Segundo Aguiar e Ozella (2006), sentido é mais abrangente que significado, já que este não segue uma 
lógica social e sim uma interpretação subjetiva, permeada pela emoção e pelos processos afetivos e cognitivos.

Para Vigotski (1993), a relação sujeito e objeto é mediada por signos: ao aprender uma palavra ou gestual corporal se aprende seus significados e signos. Significado é aquilo que faz sentido para os outros, ou seja, "conteúdos instituídos e compartilhados socialmente". Sentido é aquilo, dos outros, que faz sentido para o indivíduo, quer dizer, "aspectos gerados pelas experiências particulares" (STOROLI, 2007, p.21).

O desenvolvimento cultural (sócio histórico) proposto por Vigotski segue uma abordagem dialética, ou seja, uma lógica e uma metodologia processual, ruptiva, construtiva (e reconstrutiva), conflitiva e interacionista. Para Leontiev (1978), esta construção dialética do indivíduo é fruto de conversões culturais e só ocorre por mediação da sociedade. A mediação semiótica são as significações produzidas por nós, para os signos (linguagens), e legitimadas pelo outro (SIRGADO, 2000a).

A semiótica apresenta relação com a semântica, indicando significações produzidas por nós mesmos. Por meio da mediação semiótica é possível explicar os processos de internalização e objetivação (SIRGADO, 2000b). Para Vigotski, existem dois mediadores externos: os instrumentos (que regulam as ações sobre os objetos) e os signos (que regulam as ações sobre o psiquismo das pessoas). Os signos são reversíveis e, portanto, aptos à regulação do próprio sujeito; por isso são considerados mediadores na formação da consciência.

É pela mediação dos signos que uma pessoa se torna parte da sua comunidade, internalizando as culturas que a permeiam e tornando-se um indivíduo social, humanizado. Se o objeto a ser internalizado é a significação das coisas e não as coisas 
em si, portanto o que é internalizado das relações sociais é a significação que elas tem para as pessoas; significação que emerge na própria relação.

Para Vigotski, o principal signo mediador do desenvolvimento (social, cultural e individual) humano é a linguagem. Cabe aqui destacar que linguagem não se remete apenas à fala, mas também a outros tipos de linguagens, como por exemplo, a gestual, a musical e a corporal. E estas múltiplas linguagens são, normalmente, contempladas como conteúdos de projetos sociais.

\section{PROJETOS SOCIAIS}

Para Couto e Couto (2011), os projetos sociais tem por princípio promover mudanças na vida de seus beneficiários, "proporcionando um ambiente social mais justo e democrático" (p.83). Os projetos sociais surgem das expectativas de solução ou minimização das mazelas sociais e baseiam-se geralmente nos temas que levam a uma profunda reflexão das diferentes realidades nacionais, necessitando de organização para que obtenham êxito em sua execução. Para Ander-Eggs e Idañes (1997) e Couto e Couto (2011), nenhum projeto terá êxito se não deliberar um grande esforço de organização; desta forma, a organização e execução, deve se pautar na realidade local e agir então de acordo com as necessidades. Além disso, bons projetos sociais não dependem somente de boas intenções, mas também de eficiência operativa, ou seja, a capacidade de transformas as ideias propostas no planejamento em ações deliberadas na prática na comunidade.

Grande parte dos projetos sociais, conta com o trabalho voluntário, quer dizer, as iniciativas individuais ou coletivas de membros da própria comunidade, mas também 
conta com a participação de pessoal especializado, pois toda transformação, está atrelada a uma dimensão técnica e teórica e, portanto, é preciso que haja o agente direcionador do projeto. Este responsável, monitor, professor ou educador, é quem deve orientar as ações, as oficinas e os demais colaboradores e buscar os objetivos propostos de acordo com o planejamento e a satisfação das metas predefinidas. Portanto, os projetos esportivos sociais tem na educação física uma importante aliada. Para Tabares (2006), o lazer e o esporte são considerados os melhores mediadores do desenvolvimento humano e por essa razão encontram-se sempre inseridos em programas sociais, governamentais ou não governamentais.

Os projetos sociais não se caracterizam como ações isoladas, ou seja, não funcionam sozinhos, se interagem sempre em vários modelos de relações, com políticas e programas voltados para o social (SILVEIRA, 2013). Neste sentido, os projetos podem tanto funcionar como indutores de novas políticas públicas, quanto atuarem na gestão e execução de políticas já existentes. No ambiente escolar, por exemplo, o professor de educação física pode e deve usar de sua função para desenvolver no contra turno das aulas um projeto esportivo social para que, dessa forma, ocupe de forma produtiva o tempo ocioso dos alunos (PINTO, 2012). Cabe esclarecer a expressão “ocupação produtiva do tempo ocioso": tempo ocioso não se remete necessariamente a algo negativo, pelo contrário, pois tempo livre é uma conquista e um direito. Quando nos referimos a ocupação estamos nos referindo a ampliação das oportunidades de socialização, de acesso às práticas corporais, informação e oportunidade de experiências culturais (PALHARES, 2012).

Por outro lado, os participantes dessas atividades, estarão não somente aperfeiçoando suas habilidades corporais, mas também estreitando seus laços sociais 
com colegas, professor e demais agentes locais. Além disso, o professor pode e deve promover outras atividades para além da prática corporal, tipo palestras de cunho pedagógico que despertem alunos, familiares e a comunidade local com temas pertinentes à sua realidade social e a realidade do seu país, bem como outras propostas. A temática de um projeto social procura passar para o jovem inscrito no programa social os conhecimentos sob forma alternativa de aprendizagem, fugindo daquele contexto da educação formal das escolas tradicionais. Desta forma, são várias as estratégias usadas, como os debates, as oficinas, as rodas de terapia comunitária, os ensinamentos através das práticas corporais, por meio de uma infinidade de metodologias.

Os projetos esportivos sociais, também denominados por Gomes e Constantino (2005) de projetos esportivos de inclusão social, atraem grande público e são de fácil aceitação e os principais motivos para tal se justificam no amplo leque de possibilidades da cultura corporal, no custo relativamente baixo de implantação e nas novidades que os projetos esportivos sociais levam até as comunidades. Por outro lado, para Vianna e Lovisolo (2009), existe também uma "não adesão" e uma alta taxa de abandono dos projetos, que atualmente não são questionados pelos coordenadores dos projetos, nem pelas instituições proponentes e muito menos é veiculado na mídia. Não pretendemos aqui fazer uma apologia dos projetos esportivos sociais e nem mesmo aponta-los como uma possível "cura social”, mas apontar seus benefícios e importância, consciente do que tem de ser feito para alcança-los e mantê-los.

Cabe aqui uma breve discussão sobre inclusão social, termo difundido e utilizado atualmente e geralmente vinculado aos projetos sociais. Segundo Palhares (2012), quando se fala em inclusão social duas imagens são vislumbradas: pessoas menos favorecidas economicamente ou com alguma necessidade especial. Mais uma 
vez o foco é dicotômico, ou seja, a necessidade de se rotular ou segregar a sociedade em grupos, como se expor um conjunto de pessoas em função de alguma característica contribuísse para seu auxílio. E as crianças ricas e abastadas, que vivem em um mundo blindado, também não precisam ser incluídas? E aqueles jovens que não apresentam qualquer deficiência física ou mental, também não necessitam de inclusão para aprenderem a se colocar no lugar dos outros e assim respeitar e contribuir? Afinal, quem de nós não apresenta alguma necessidade especial, seja ela física, econômica, social, afetiva, educacional ou psicológica? Assim, em um projeto social a inclusão pode ser entendida como o processo que contribui para um indivíduo tornar-se um membro, crítico e consciente, da sociedade (PALHARES, 2012).

Dentre as várias práticas corporais que podem ser utilizadas nos projetos esportivos sociais, escolhemos discutir a capoeira. Esta escolha não se dá aleatoriamente, pois a capoeira apresenta-se com um viés educacional para alunos de projetos sociais por se basear em suas características mais marcantes: ter uma origem afro-brasileira, possuir raízes negras como a maioria do nosso povo, possuir grande identificação histórica e por apresentar um baixo custo de implantação.

\section{PROJETOS ESPORTIVOS SOCIAIS E A CAPOEIRA}

Os projetos esportivos sociais, de uma forma geral, abrangem uma infinidade de conteúdos e métodos a serem utilizados para os fins pretendidos (GOMES; CONSTANTINO, 2005; RODRIGUES; DARIDO; PAES, 2013): são vários os esportes, jogos, brincadeiras, danças e lutas com potencial para se inserirem nesse contexto educacional e passarem a mensagem pretendida. Dentre as várias propostas e enfoques especificaremos a capoeira e o seu viés educacional: uma capoeira 
pedagogicamente estruturada, com finalidades reflexivas e críticas a respeito de preconceitos raciais e sociais de nosso tempo (FALCÃO, 1996; BUSS-SIMÃO; FIAMONCINI, 2013). Para tanto, devemos considerar quem está mediando a prática, quem é o público-alvo, qual é o contexto e qual a proposta pedagógica (PALHARES, 2007).

Segundo Santos e Palhares (2012), a capoeira, desde os seus primórdios, sempre foi meio de educação e, durante muito tempo, foi o principal acesso à cultura e a arte, principalmente para os negros, os economicamente desfavorecidos e aqueles que sofreram algum tipo de preconceito. Após a publicação da obra "Subsídios para o estudo da metodologia do treinamento da capoeiragem", de Inezil Penna Marinho, em 1945, a capoeira passou a ser vista como método ginástico brasileiro, passando, portanto a ser praticada como educação física.

Para Frigerio (1989), a capoeira pode ser um contexto de educação - social e cultural. Não se trata em si da prática da arte, mas sim da vivência do aluno de suas ideologias e históricos. Evidentemente que não se pode negar os gestos técnicos, contudo a capoeira nesse sentido não tem a pretensão de ser aprendida de fato de acordo com um padrão pré-estabelecido, mas sim de exercitá-la com objetivos críticos. Assim, percebe-se que, para Frigerio (1989), o que importa para o aluno é a relação da capoeira com o conteúdo proposto e a relação entre aluno e professor: os dois devem estabelecer juntos um plano de trabalho, onde ficará claro o papel de cada um nesse processo ensino e aprendizagem. Para Leontiev (1978), esta construção dialética do indivíduo é fruto de conversões culturais - do social para o individual - e só ocorre por mediação do grupo o qual este indivíduo pertence. 
Para Nogueira (2007), a prática da capoeira contribui para a socialização, aquisição de valores e conhecimentos culturais, possibilitando a seus praticantes a ampliação de seu espectro de visão de mundo e uma possível (re) inserção na sociedade, a partir da perspectiva cultural de um determinado grupo, perspectiva esta que delineia as relações sociais. Para Ingold (2008), os seres humanos dependem de habilidades culturalmente adquiridas e tais habilidades são fruto de prática prolongada e frequente. $\mathrm{Na}$ capoeira tal premissa se confirma, pois as habilidades corporais, rítmicas e musicais só são apreendidas por meio de prática. No entanto, capoeiristas de um mesmo grupo e até mesmo discípulos de um mesmo Mestre, por mais que pratiquem as mesmas habilidades ainda assim apresentam formas particulares de gingar, se movimentar e tocam os mesmos instrumentos, os mesmos acordes de forma distinta, individual. Tim Ingold explica tal fenômeno por meio da tradição cultural, ou seja, apesar do aprendizado de algumas habilidades da capoeira ser permeado por regras e representações impostas aos capoeiristas, as características concretas de sua execução são determinadas socialmente e culturalmente. E como cada indivíduo se apropria ao seu modo dos signos (por exemplo, na capoeira: o movimentar-se, os ritmos e os rituais de uma roda), portanto, tal processo é individual e único; apesar de ocorrer em um ambiente social, na coletividade.

Portanto, a capoeira neste contexto não se trata de uma reprodução de modelos predeterminados, mas sim de uma compreensão de seus elementos e do mundo através de uma abordagem crítica, visando criar no aluno uma melhor percepção da sua realidade, consequentemente o preparando para o mundo. Baseado nos argumentos descritos acima se tende a pensar a capoeira nos diferentes contextos de educação, pois além da cultura corporal, traz consigo elementos de extrema necessidade à vida de 
jovens incluídos em projetos e programas sociais, constituindo-se dessa forma de valores indispensáveis à vida social.

Ao longo da história, o significado social da capoeira se altera de acordo com o lugar social do negro no interior da sociedade brasileira. Para se promover a inclusão social através da capoeira, torna-se fundamental ampliar os tempos e os espaços para a prática, promover o debate relacionando seus conteúdos históricos, culturais e técnicos e, especialmente, garantir a experiência de uma de suas características mais essenciais: a ludicidade. A experiência da capoeira em projetos sociais permite aos seus praticantes o desenvolvimento da possibilidade de criar, brincar, sorrir ou como se diz no meio capoeirístico, vadiar. Desta forma, a capoeira se torna um elemento dinâmico de produção, e não apenas de reprodução, de cultura. Na capoeira, contraditoriamente, os praticantes se diferenciam pela cultura, quer dizer, aquilo que os une em um mesmo propósito e também os tornam semelhantes é o mesmo que os distingue uns dos outros! E somente as propriedades de auto-organização dinâmica dos sistemas em desenvolvimento podem ajudar a refletir as possíveis consequências destas mudanças evolutivas (INGOLD, 2008).

Em relação a socialização por meio da cultura voltamos a nos remeter à abordagem histórico-cultural, de Vigotski: referencial teórico pelo qual buscamos explicar as aprendizagens a partir das relações sociais e experiências, mediadas e significadas, por um grupo de capoeira e convertidas pelos capoeiristas. Algumas pessoas após se inserirem na capoeira passam a internalizar signos próprios desse fenômeno social. E com o passar do tempo, um tempo historicamente constituído de experiências eminentemente práticas e afetivas, estas pessoas passam a significar tais signos os convertendo para um novo modo de pensar, falar e agir. 
E indo além, em conformidade com a proposta de desenvolvimento cultural de Vigotski (1991; 1993), estes sujeitos passam a se ver e a serem vistos, inclusive em outros ambientes (por exemplo: trabalho, estudo e família), por meio dessa outra significação social e cultural que permeia seu "novo" eu, constituído pela práxis da capoeira.

Muitos capoeiristas se constituem indivíduos, social e culturalmente ativos e conscientes, devido à imersão em um grupo de capoeira e em constante interação com outros capoeiristas e, principalmente, com seu Mestre: tido por muitos como um verdadeiro educador social. Os grupos são uma reunião de pessoas que se unem através do que Cordeiro (2007) descreve como referencial cultural: conjunto de valores, crenças, costumes, rituais, tradições e formas de aprendizagem, que passa a constituir uma identidade cultural, individual e coletiva e, consequentemente, a identidade pessoal. Assim, é pertinente e relevante compreender, incentivar e disseminar como esse processo educativo "[...] de construção/afirmação de identidade étnico-cultural e os reflexos do mesmo na sua práxis pedagógica" (SANTOS, 2004, p.59) ocorre dentro da instituição de ensino grupo de capoeira.

\section{CONSIDERAÇÕES FINAIS}

Os projetos esportivos sociais transcendem os muros das escolas e seus conteúdos e podem ser executados sobre várias formas metodológicas, sendo as mais usadas as oficinas, com destaque para as artes, cultura e lazer. De acordo com Palhares (2012) e Couto e Couto (2011), estes projetos tem como missão proporcionar que crianças e jovens possam construir coletivamente a sua história com o auxílio dos conteúdos da cultura corporal de movimento. Por apresentar elementos pertinentes de 
uma educação baseada em um desenvolvimento cultural, aprendizagens adquiridas por significações mediadas e uma formação, individual e social, dialética, a capoeira possui elementos característicos de grande importância na vida social de crianças e jovens.

Dessa forma, acreditamos que os projetos esportivos sociais, podem contribuir de forma significativa, pois torna perceptível as mudanças de comportamento, formação intelectual e social em seus participantes. Os jovens abrem sua mente para uma nova realidade, até então desconhecida, e desta forma entram na vida adulta mais preparados, recuperando ou reforçando sua auto estima e superando seus próprios limites (ABIB, 2005). Por fim, sugerimos que a ampliação do uso da capoeira em projetos sociais, inclusive nos espaços formais de ensino, entendendo que ela possibilita a seus praticantes tornarem-se agentes produtores de cultura.

\section{REFERÊNCIAS}

ABIB, P.R.J. Capoeira angola: cultura popular e o jogo dos saberes na roda. Salvador: EDUFBA, 2005.

AGUIAR, W.M.J.; OZELLA, S. Núcleo de significação como instrumento para a apreensão da constituição dos sentidos. Revista Psicologia: Ciência e Profissão. Brasília, v.26, n.2, p.222-245, 2006.

ANDER-EGG, E.; IDÁÑEZ, M.J.A. Cómo elaborar un proyecto: guia para diseñar proyectos sociales y culturales. Madrid: Instituto de Ciencias Sociales Aplicadas, 1997.

BUSS-SIMÃO, M.; FIAMONCINI, L. Educação física na educação infantil: reflexões sobre a possibilidade de trabalhos com projetos. Revista Pensar a Prática, Goiânia, v.16, n.1, p.297-314, 2013.

CASTEL, R. As metamorfoses da questão social: uma crônica do salário. Petrópolis: Vozes, 1999.

CASTRO, M.G.; ABRAMOVAY, M. Cultura, identidades e cidadania: experiência com adolescentes em situação de risco. In: COMISSÃO NACIONAL DE POPULAÇÃO E DESENVOLVIMENTO. Jovens acontecendo nas trilhas das políticas públicas. Brasília: CNPD/Ipea, 1998, p.571-642. 
CORDEIRO, Y.C. A participação da prática da capoeira no processo de constituição da identidade adolescente. 2007. 131f. Dissertação (Mestrado em Psicologia) - Universidade Católica de Brasília, Brasília, 2007.

COUTO, A.C.P.; COUTO, M.A. A gestão de projetos sociais e o lazer. In: ISAYAMA, H.F.; SILVA, S.R. (Org.). Estudos do lazer: um panorama. Rio de Janeiro: Apicuri, 2011, p.81-95.

FALCÃO, J.L.C. A escolarização da capoeira. Brasília: Royal Court Editora, 1996.

FARIA, E.L.; et al. Lazer e educação: abordando as práticas culturais de crianças e jovens como contexto de aprendizagem. In: ISAYAMA, H.F.; SILVA, S.R. (Org.). Estudos do lazer: um panorama. Rio de Janeiro: Apicuri, 2011, p.7-33.

FREIRE, P. Pedagogia do oprimido. Rio de Janeiro: Paz e Terra, 1980. FRIGERIO, A. Capoeira: de arte negra a esporte branco. Revista Brasileira de Ciências Sociais, Rio de Janeiro: v.4, n.10, p.85-98, 1989.

GOHN, M.G.M. A Educação não formal e a relação escola comunidade. Eccos Revista $\begin{array}{llllll}\text { Científica, São } & \text { Paulo, } & \text { v.6, } & \text { n.2, } & \text { p.39-65, } & \end{array}$ GOHN, M.G.M. Educação não formal, participação da sociedade civil e estruturas colegiadas nas escolas. Ensaio, Rio de Janeiro, v.14, n.50, p.27-38, 2006.

GOMES, M.C.; CONSTANTINO, M.T. Projetos esportivos de inclusão social - PIS: crianças e jovens. In: DA COSTA, L.P. (Org.) Atlas de esporte no Brasil: atlas do esporte, educação física e atividade física de saúde e lazer no Brasil. Rio de Janeiro: Shape, 2005, p.602-612. IBGE - Instituto Brasileiro de Geografia e Estatística. Censo Demográfico. 2000. Disponível em: http://www.ibge.gov.br. Acessado em 06 de Julho de 2013. INGOLD, T. Tres en uno: cómo disolver las distinciones entre cuerpo, mente y cultura. In: CRIADO, T.S. (Ed.). Tecnogénesis: la construcción técnica de las ecologías humanas, Madrid: AIRB, v. 2, 2008, p.73-88.

LEONTIEV, A.N. O desenvolvimento do psiquismo. Lisboa: Horizonte, 1978.

MARCELINO N. Lazer e educação. Campinas: Papirus, 2004.

NARANG, R.H. Social justice and political education through non-formal education. International Review of Education, Cham/Suíça, v.38, n.5, p.542-546, 1992.

NOGUEIRA, S.G. Processos educativos da capoeira angola e construção do pertencimento étnico-racial. 2007. 173f. Dissertação (Mestrado em Educação) Universidade Federal de São Carlos, São Carlos, 2007.

PALHARES, L.R. Educação e cultura popular: inclusão social pela capoeira. Licere, Belo Horizonte, v.10, n.3, a.4, 2007.

PALHARES, L.R. Capoeira e projetos sociais. Revista Vozes dos Vales, Diamantina, v.1, n.1, a.16, 2012. 
PINTO, C.A.S. Esporte educacional: uma possibilidade de restauração do esporte. Revista Mineira de Educação Física, Viçosa, v.20, n.1, p.162-177, 2012. RODRIGUES, H.A.; DARIDO, S.C.; PAES, R.R. O esporte coletivo no contexto dos projetos esportivos de inclusão social: contribuições a partir do referencial técnico-tático e sócio-educativo. Revista Pensar a Prática, Goiânia, v.16, n.2, p.323-339, 2013.

SANTOS, I.P. Capoeira: educação e identidade étnico-cultural em grupos/academias da cidade de Salvador-BA. Sitientibus, Feira de Santana, n.30, p.47-60, 2004.

SANTOS, D.R.; PALHARES, L.R. Construção histórica da capoeira: as voltas que o mundo dá... Revista EF Deportes, Buenos Aires, v.17, n.174, 2012.

SILVEIRA, J. Considerações sobre o esporte e o lazer: entre direitos sociais e projetos sociais. Licere, Belo Horizonte, v.16, n.1, 2013.

SIRGADO, A.P. O social e o cultural na obra de Vigotski. Educação e Sociedade, Campinas, v.21, n.71, p.45-78, 2000a.

SIRGADO, A.P. O conceito de mediação semiótica em Vigotski e seu papel na explicação do psiquismo. Cadernos CEDES, n.24, p.32-50, 2000 b.

SMOLKA, A.L.B. O (im)próprio e o (im)pertinente na apropriação das práticas sociais. Cadernos CEDES, Campinas, n.50, p.26-40, 2000.

SOUZA, D.L.; CASTRO, S.B.E.; VIALICH, A.L. Barreiras e facilitadores para a participação de crianças e adolescentes em um projeto socioesportivo. Revista Brasileira de Ciências do Esporte, Campinas, v.34, n.3, p.761-774, 2012.

SOUZA, D.L.; et al. Determinantes para a implementação de um projeto social. Revista Motriz, Rio Claro, v.16, n.3, p.689-700, 2010.

STOROLI, F.Q. Inclusão social e esporte: os significados-sentidos da capoeira para adolescentes em situação de pobreza. 2007. 145f. Dissertação (Mestrado em Psicologia Social) - Pontifícia Universidade Católica de São Paulo, São Paulo, 2007.

TABARES, J.F. O esporte e a recreação como dispositivos para a atenção da população em situação de vulnerabilidade social. In: MELLO, V.A; TAVARES, C. O exercício reflexivo do movimento: educação física, lazer, e inclusão social. Rio de Janeiro: Shape, 2006, p.212-224.

THOMASSIM, L.E.C. Uma alternativa metodológica para análise dos projetos sociais esportivos. In: ENAREL - ENCONTRO NACIONAL DE RECREAÇÃO, ESPORTE E LAZER, 18., 2006, Curitiba. Anais... Curitiba: Pontifícia Universidade Católica, 2006.

VIANNA, J.A.; LOVISOLO, H.R. Projetos de incluso social através do esporte: notas sobre a avaliação. Movimento, Porto Alegre, v.15, n.3, p.145-162, 2009.

VYGOTSKY, L.S. A formação social da mente. São Paulo: Martins Fontes, 1991. 
VYGOTSKY, L.S. Pensamiento y Palabra. In: VYGOTSKY, L.S. Obras Escogidas, Tomo II. Madrid: Visor Distribuciones, 1993, p.287-348.

VYGOTSKY, L.S.; LURIA, A.R. Estudos sobre a história do comportamento: o macaco, o primitivo e a criança. Porto Alegre: ArtMed, 1996.

\section{Endereço dos Autores:}

Carlos Sérgio Rabelo da Conceição

Leandro Ribeiro Palhares

Rua Ametista, 201 - Residencial Vale dos Diamantes

Diamantina - MG - 39100-000

Endereço Eletrônico: leandro_palhares@yahoo.com.br 